\title{
Environmental training at companies. The case of Volkswagen Navarra
}

\author{
Ormazabal, Marta; Viles, Elisabeth; Prieto-Sandoval, Vanessa and Jaca, Carmen \\ Department of Industrial Management, Tecnun - University of Navarra, Spain
}

\begin{abstract}
Companies have made great strides in strengthening their environmental maturity and sustainable production. Nevertheless, many of them have not transmitted their knowledge to their workers, and this makes it more difficult to have employees participate in their company's sustainability improvement process. In the particular case of Volkswagen Navarra, they have a lot of experience in environmental management, but they don't have a proper program for teaching their workers so they can be more involved in the environmental aspects of the company. This paper proposes an environmental training program that can be used either as an e-learning course or a faceto-face course with the objective of providing employees with the knowledge and skills necessary to participate in the improvement of environmental aspects.
\end{abstract}

Keywords: environmental management, training, course, company 


\section{Introduction}

The intensive use of natural resources to produce goods and services has led to a large increase in the generation of waste. It has been estimated that "we are more than ten times better at wasting resources than at using them" (Von Weizsäcker et al., 1998). Fortunately, society is becoming increasingly concerned about the environment. Similarly, customers are becoming more aware of resource depletion and companies' desire to continuously improve environmental management and measures (Claver et al., 2007).

Moreover, since the publication of "Our Common Future" and "The Brundtland Report" governments and institutions have encouraged the development of less polluting processes and products (Brundtland Commission, 1987), and current policy makers are oriented toward boosting circular business models that are in line with nature. One such example is the European Commission's (2015) action plan for the Circular Economy. Specifically, since the beginning of the new millennium, companies have greatly strengthened their environmental management by accepting the responsibility that each entity has and its transcendental role in society (Labuschagne et al., 2005). Governments and companies are becoming more aware of the necessity of not only creating eco-friendly products but also improving their production processes in an environmentally friendly way. There are many international environmental standards that might be useful for companies that are willing to improve. These standards provide specifications and guidelines for environmental management systems, environmental audits, eco-design, eco-labeling, life cycle assessment, environmental behavior evaluation and environmental communication (Aenor, 2008).

In order to improve the quality and ecological performance in a sustainable way, it is important that companies to implement a continuous improvement system in which a series of factors need to be developed: information and communication systems, the creation of a culture of improvement, appropriate training, commitment and participation of the workers, management and monitoring of the improvement system (Bateman and Rich, 2003), among others.

Jurburg et al. (2016) posit that "the best way of training [employees] to participate in the continuous improvement system is learning by doing, and therefore, everybody should be involved in the learning process". Some models that explain the sustainability of continuous improvement as an evolutionary process of skills acquisition define as excellent those companies that follow the concept of "learning organization" (Bessant et al., 2001). However, according to a recent study done on companies considered to be excellent in management, many of the necessary habits are not yet fully ingrained; for example, it was found that there is a general lack of documentation on past activities (Jurburg et al., 2015).

Therefore, the main objective of this study is to create a training package that will allow companies to train their employees with the purpose of making employees aware of the 
importance of evaluating and monitoring the environmental impact of their work while at the same time informing them of the environmental actions that the company is carrying out to achieve environmental goals. As a consequence of this training, the workers will be more aware of the importance of environmental management and they will be more prepared to get involved in the company's continuous improvement activities that are aligned with its environmental objectives. In this way, a culture of environmental management is created.

\section{Method. The Case of Volkswagen Navarra}

This study was carried out at Volkswagen Navarra, S.A., one of the 119 factories that the Volkswagen Group has all over the world. Located in Pamplona (Navarra), this factory has been producing the Polo for the whole world without interruption since 1984.

Volkswagen Navarra has been actively interested in the environment since the end of 1995, when they began to develop their Environmental Management System, which eventually led to the creation of the Environmental Department at the end of 1996. It should be noted that in 1997, Volkswagen Navarra became the first company in the automotive sector at the European level to obtain ISO 14001 certification and the first automotive factory in Spain to earn EMAS certification. Since then, Volkswagen Navarra has been very aware of environmental aspects all throughout its manufacturing process, focusing on improving waste management and energy efficiency and reducing the environmental impact of its processes. In addition, in November 2010, Volkswagen Navarra became the first company in the automotive industry to obtain ISO 16001 certification for its Energy Management System. Despite of the recent prestige controversy related to environmental issues in the automotive sector, this factory history proves the high degree of Volkswagen Navarra's involvement in environmental management and the company's environmental knowledge. In this sense, the employees engagement is quite important because theory and practice indicate that "all employees are environmental managers" (Cohen-Rosenthal, 2000).

Given the above, we believe that more value would be created in the company if all employees were aware of the ecological improvement projects that have been carried out and the environmental knowledge that has been generated by their company since the 1990s.

The main objective of this project is to create a training package so anyone in the Volkswagen Navarra's plant can understand the importance of environmental management and how they can contribute to its improvement from their own positions of responsibility. This training package has been created with the collaboration of the Sustainable 
Improvement team at the University of Navarra, as they understand the environmental challenges that companies face and they are experts in training.

\subsection{Training package design}

The training package has been designed according to the following propositions:

- Raise awareness about environmental aspects. For this purpose, a static part containing novel content about the environment was developed in order to provide an overview of the subject. Therefore, the main idea of the static part is that it is not an updatable section; if modification have to be made, the vast majority of information is kept in its original form. All the data that is used in this section is related to daily activities so participants can have a better understanding of the magnitude of the environmental problem taught.

- Show the environmental actions that are carried out at the plant and their results. This part is dynamic as the content can be updated according to the new actions that are developed. Workers can gain a better understanding of what kind of improvements they can carry out in their own work and what results they can obtain.

- Assess knowledge acquired. It is important to verify that the information is correctly assimilated by trainees. To that end, several questionnaires were developed so participants can demonstrate the degree to which they have understood the course by taking a self-examination test.

The training package should be organized and presented in a visual way so it is attractive to the workers taking the course. It was decided that a series of training modules would be developed based on the five "Think Blue" indicators plus an introductory module. The concept of "Think Blue" represents the long-term philosophy of the Volkswagen brand for achieving environmental sustainability based on the three fundamental pillars: ecological solutions and products, individual behavior, and environmental initiatives. Volkswagen uses the color blue to represent resources that are worthy of protection, such as water and air. Moreover, as blue is the traditional color of the Volkswagen brand, the "Think Blue" concept closely ties the brand with the environmental concepts it encompasses.

In terms of objectives, Volkswagen has set itself the goal of becoming the eco-friendliest and most economical automobile manufacturer for the year 2018. Similarly, Volkswagen Navarra has adopted the "Think Blue. Factory." strategy. The goal is to reduce by the year 2018 and for each vehicle manufactured the following indicators by 25\%: water consumption, energy consumption, non-recoverable waste, $\mathrm{CO} 2$ emissions and the emission of solvents. 
These five indicators plus the introduction compose the structure of the training package. For each of these modules a static part, a dynamic part and a self-examination test have been developed (Figure 1). It was decided that the information would be provided in the form of PowerPoint presentations and illustrative videos in order to speed up, facilitate and increase the visibility of the modules, in order to promote awareness and involvement by employees.

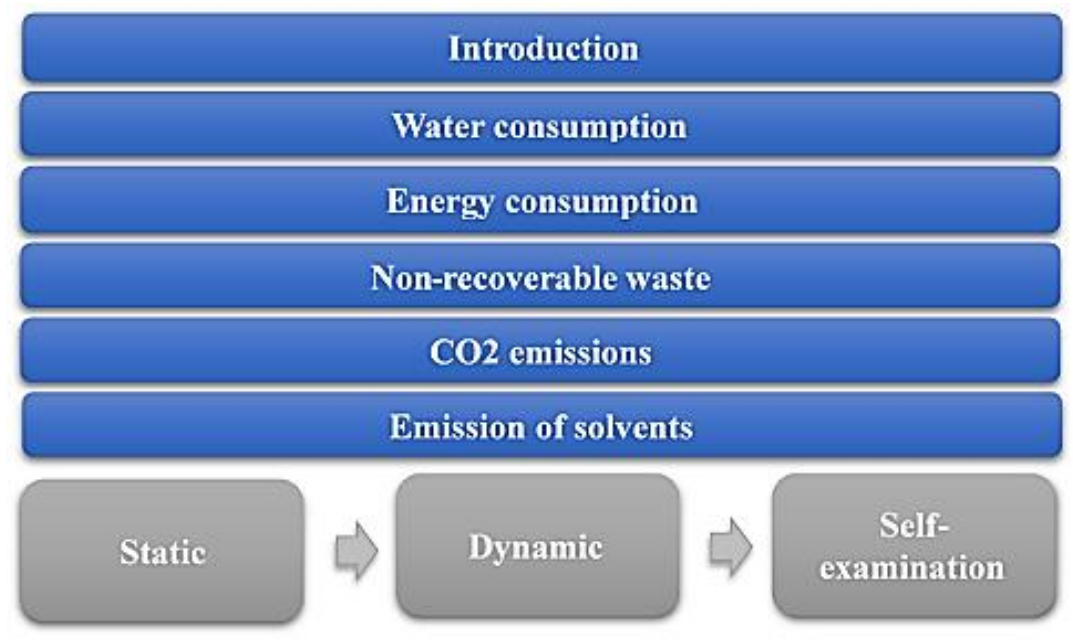

Figure 1. Training package structure

\subsection{Information Collection}

The qualitative interview is the most common and one of the most important gathering tools in qualitative research (Myers and Newman, 2007). For this reason interviews were held with the environmental managers at Volkswagen Navarra with the purpose of specifying and understanding the different environmental milestones the company has reached, as well as those that the company is planning on reaching in the near future. This task was reinforced by collecting the information that is available on the Volkswagen intranet. Interviews with people who have played an important role in the implementation of different environmental measures or actions were carried out in the same way. This task was complemented by collecting information that is available on both the Volkswagen Navarra intranet and the Group's "Management Web". In addition, external sources and sources from the literature were used to better explain the measures that have been implemented. 


\section{Results}

In starting the training course, it was decided that training material would be used for a face-to-face course with all the workers at Volkswagen Navarra. It was decided that a faceto-face course would assure that all the current employees would take the course, as the company gave the participants release time so they could take it.

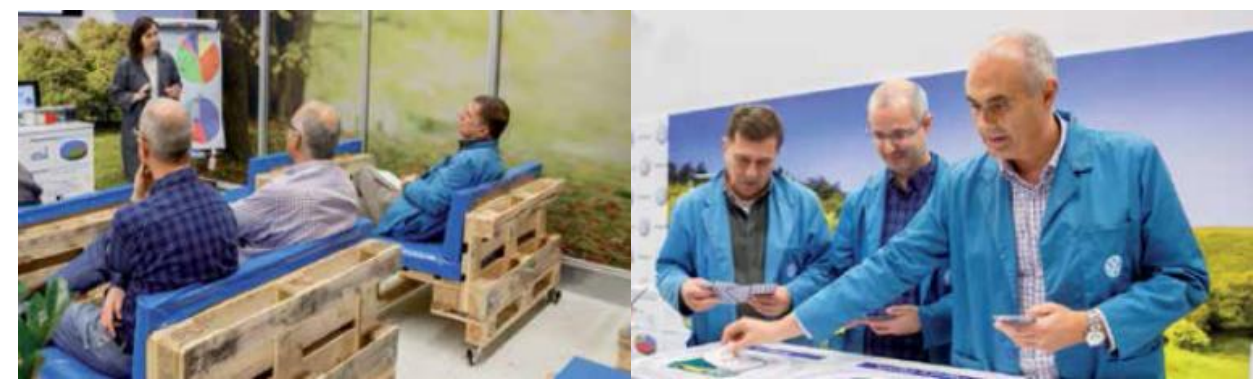

Figure 2. Employees attending the face-to-face course

This preliminary format allowed us to include some practice exercises so the workers could better understand some of the concepts (Figure 2). For example, in the energy consumption module, there is a practice activity that uses three different bulbs: an incandescent lamp, low consumption bulb and a LED light. Participants need to use a hand-crank to turn on each of the lights. The effort needed to turn on the incandescent lamp is much greater than the other two. Obviously, the easiest one to turn on is the LED light. This practical exercise makes participants more aware of the energy consumed by each of these types of lights and the importance of managing energy consumption.

A total of 48 face-to-face courses with a total of 343 employees have been run at Volkswagen Navarra, with an average of 7.15 participants per course. After each course, participants were asked to report on their satisfaction level via a questionnaire that allowed them to respond on a 4-point scale (Table 1). 
Table 1. Satisfaction questionnaire results

\begin{tabular}{cc}
\hline Item assessed & Average \\
\hline The course was well organized & 3.7 \\
The number of students in the group was appropriate for the course & 3.8 \\
The content of the course has responded to my training needs & 3.4 \\
It has allowed me to acquire new skills / abilities that I can apply to the job & 2.8 \\
It has improved my chances of changing jobs within the company or outside it & 2.5 \\
I have gained knowledge that allows me to progress in my professional career & 2.3 \\
It has favored my personal development & 2.9 \\
Degree of overall satisfaction with the course & 3.6
\end{tabular}

As can be seen, all the questions were valued above 2, and the general questions regarding the course organization, the course content and overall participant satisfaction were valued close to 4 , meaning that participants were in near total agreement with the questions.

\section{Conclusion}

The environment is a fundamental variable in the development of companies. As noted above, many companies are stuck in the process of systematizing their environmental management and do not take full advantage of environmental management within the company by not giving all the environmental information they have to their workers.

This project attempted to solve this problem by providing a specific company, Volkswagen Navarra, with materials that can be used to make employees aware of its environmental responsibility in an orderly and structured way. This project made is possible for the company to disseminate the environmental knowledge it has acquired throughout its environmental history to the company environment as a whole. Moreover, having the Sustainable Improvement group from the University of Navarra participate in the development of the training package has allowed them to include their environmental management knowledge, in addition to adapting the training modules so they would meet the company's objectives.

The result of the training courses is that all of the workers can move in the direction proposed by the company's Environmental Department, which will make it will be easier for the company to achieve its environmental objectives effectively and efficiently.

Moreover, in terms of university education, this collaboration with Volkswagen Navarra has provided us with more real examples to use in class, thereby enriching the classes and giving students a look into company life. 


\section{Acknowledgements}

The authors gratefully acknowledge financial support from Cátedra de Empresa, Volkswagen Navarra - Universidad de Navarra. The authors also want to give particular thanks to the environmental manager of Volkswagen Navarra, Ana Isabel Moreno, who has been an active participant through the entire project.

\section{References}

Aenor, 2008. Gestión ambiental. Normas UNE. AENOR, Spain.

Bateman, N., Rich, N., 2003. Companies' perceptions of inhibitors and enablers for process improvement activities. International Journal of Operations \& Production Management. 2, 185- 199.

Bessant, J., Caffyn, S., Gallagher, M., 2001. An evolutionary model of continuous improvement behaviour. Technovation. 2, 67-77.

Brundtland Commission, 1987. Our common future: Report of the World Commission on Environment and Development. UN Documents Gathering a Body of Global Agreements

Céspedes-Lorente, J., de Burgos-Jiménez, J., Álvarez-Gil, M.J., 2003. Stakeholders' environmental influence. An empirical analysis in the Spanish hotel industry. Scandinavian Journal of Management. 3, 333-358.

Claver, E., López, M.D., Molina, J.F., Tarí, J.J., 2007. Environmental management and firm performance: A case study. J. Environ. Manage. 4, 606-619.

Cohen-Rosenthal, E., 2000. A walk on the human side of industrial ecology. Am. Behav. Sci. 2, 245-264.

Cramer, J., 1998. Environmental Management: From 'fit' to 'stretch'. Bus. Strat. Env. 3, 162-172.

European Commission, 2015. Closing the Loop: An EU Action Plan for the Circular Economy.

Jurburg, D., Viles, E., Tanco, M., Mateo, R., 2016. What motivates employees to participate in continuous improvement activities?. Total Quality Management \& Business Excellence, 1-20.

Jurburg, D., Viles, E., Jaca, C., Tanco, M., 2015. Why are companies still struggling to reach higher continuous improvement maturity levels? Empirical evidence from high performance companies. The TQM Journal. 3, 316-327.

Labuschagne, C., Brent, A.C., Van Erck, R.P., 2005. Assessing the sustainability performances of industries. J. Clean. Prod. 4, 373-385.

Myers, M.D., Newman, M., 2007. The qualitative interview in IS research: Examining the craft. Information and Organization. 1, 2-26.

Von Weizsäcker, E.U., Weizsäcker, E.U., Lovins, A.B., Lovins, L.H., 1998. Factor four: doubling wealth-halving resource use: the new report to the Club of Rome. Earthscan. 